\title{
PROTOTIPAGEM RÁPIDA EM ODONTOLOGIA
}

Mariana SCHAFFER; Nelson Luis Barbosa REBELLATO; Delson João da COSTA; Paulo Roberto MÜLLER

A palavra prototipagem significa o ato de produzir um protótipo e de preferência que seja rápido. A finalidade básica de qualquer protótipo é ser avaliado, aprovado ou corrigido, antes do início da produção em larga escala. Antigamente estes protótipos eram usados apenas na área da engenharia, com o desenvolvimento da informática e da tomografia computadorizada, eles passaram a também ser utilizado na área da saúde, possibilitando a visualização e a reconstrução tridimensional do esqueleto humano. O modelo médico é a reprodução fiel da anatomia do paciente, que é única. A utilização da prototipagem teve início na década de 80 e vem se tornando popular na área da saúde; na odontologia são utilizados principalmente na área da cirurgia e traumatologia buco-maxilo-faciais e na implantodontia. Os modelos impressos auxiliam o profissional no diagnóstico e planejamento cirúrgico, aumentando a precisão e rapidez dos procedimentos, reduzindo riscos cirúrgicos, tempos e custos hospitalares, além de estimular a confiança do paciente. Neste trabalho será apresentado o histórico da prototipagem rápida, suas indicações, vantagens e limitações. 